\title{
THE PRÆCORDIAL T DEFLECTION OF THE ELECTROCARDIOGRAM
}

\author{
BY \\ A. J. BRINK* AND J. F. GOODWIN \\ From the Department of Medicine, Postgraduate Medical School of London \\ Received November 8, 1951
}

The variations in the behaviour of the $\mathrm{T}$ deflection of the human electrocardiogram in the præcordial positions V1-V4 observed in certain experimental and clinical conditions gives some information on the origin and composition of this wave. By relating the anatomical site of muscle involvement with the observed changes in the $T$ wave, objective evidence as to the order of the repolarization process in the human heart can be presented. The clinical significance of different patterns of $\mathrm{T}$ wave inversion can be discussed as a result of these observations. An explanation of the possible mechanism underlying $\mathrm{T}$ wave inversion can also be attempted.

\section{InVERSION OF THE T WAVE BY CoOling THE PreCORDIUM}

Cooling the præcordium by means of an ice-bag will produce negativity of $T$ waves previously recorded as positive in the leads reflecting potentials from the heart muscle underlying the cooled area of chest wall V1-V4 (Brink, 1951). The electrocardiograms shown in Fig. 1 were taken before and after cooling the anterior chest wall of a young, healthy man. The following points deserve particular notice.

(1) The time taken for the cooling process to produce this change was approximately 40 minutes. This suggests that the lowering of the temperature on the outer surface of the heart only takes place after the chest wall has been sufficiently cooled to permit such deep penetration of effect. In patients who have thick chest walls, or in whom one may expect that much lung tissue is interposed between the chest wall and the heart, this local effect is increasingly difficult to produce. Thus, young people were found to be more suitable for the demonstration of the cooling effect. After the age of 30 , one only rarely manages to show any change in $\mathrm{T}$ wave form by cooling.

(2) The change in $T$ wave direction is limited to leads in the frontal plane. The standard leads and unipolar limb leads remain unchanged. This again indicates that the cooling effect produces only a very local change in the cardiac muscle.

(3) In Fig. 1c two complexes taken in the position VB are shown. The first was taken before cooling was commenced; the second after cooling had been completed. It is seen that as $\mathrm{T}$ became negative anteriorly, it gained in voltage posteriorly. Fig. 2 demonstrates the order in which the $\mathrm{T}$ wave negativity starts and comes to completion, and the order in which it recovers from the effects of cooling ( $a$ and $b$ ). The first change to take place can clearly be seen to be an aberration of the terminal portion of the $T$ wave. This end portion then becomes negative, resulting in a biphasic up-down deflection. As cooling is continued the negativity extends to involve earlier portions of the $T$ deflection. The recovery process again illustrates that the end part of the $T$ is the last to regain its former positivity. If we now accept that the effect of cooling is to produce local changes in the heart muscle, these changes must therefore extend inwards from the pericardial

* Cecil John Adams and Council for Scientific and Industrial Research Travelling Fellow. 


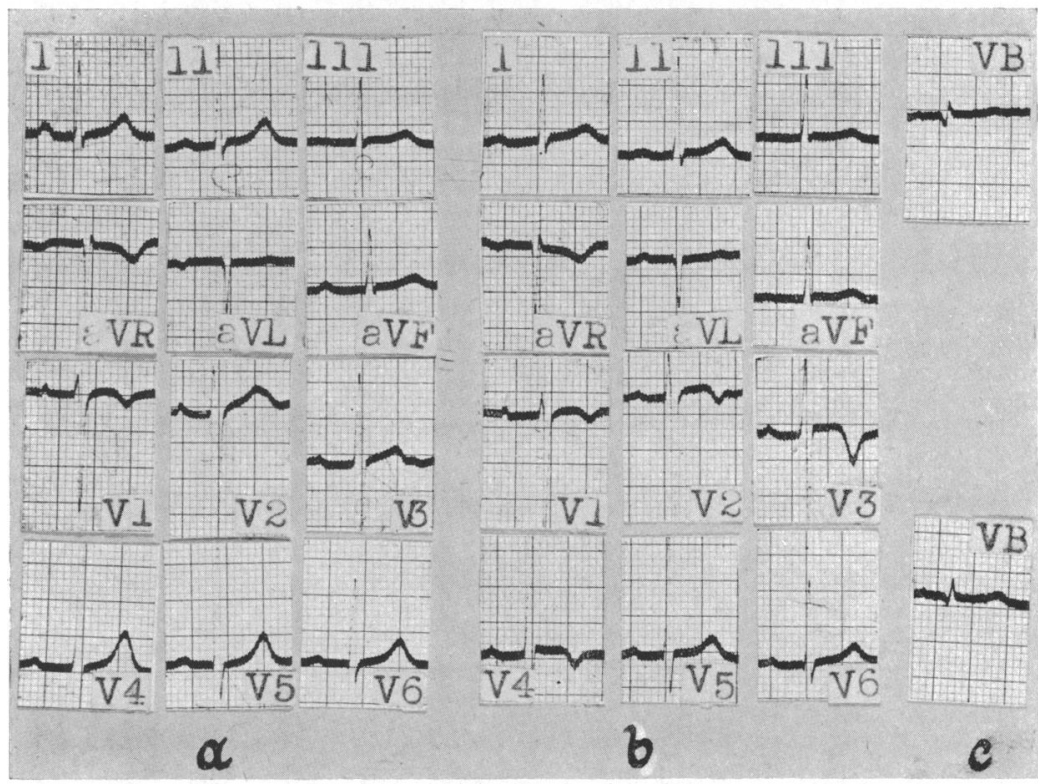

FIG. 1.-Effects of cooling the præcordium by means of an ice bag. (a) Taken before cooling. (b) Taken after cooling for 40 minutes. (c) Lead VB before and after cooling.

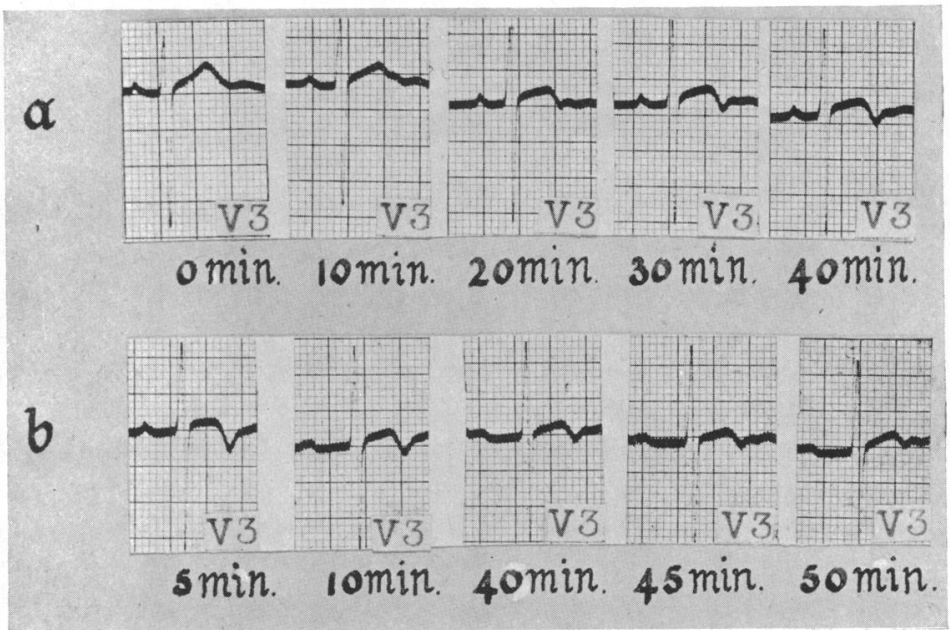

FIG. 2.-Development of electrocardiographic changes resulting from cooling the chest wall. (a) V3 showing progressive $T$ wave inversion, starting in the terminal portion. (b) Progressive $\mathrm{T}$ wave recovery ending in the terminal portion.

aspect. Since the end of the $T$ deflection marks the end of the repolarization process in the heart muscle, we must assume that this terminal repolarizing process arises subpericardially, and that the earliest forces of repolarization come from the more deeply situated muscle. This behaviour of the $T$ wave therefore suggests that the wave of recovery begins subendocardially and spreads outward through the heart muscle. It appears to follow the same course, therefore, as does the depolarizing wave. We would therefore have to infer that the first muscle to become active is also the first to recover. This view is not the one more generally held (Ashman and Hull, 1944). 


\section{The Change Produced by Local Muscle Damage}

Case 1. In Fig. 3 is shown the electrocardiogram of a man aged 66, taken two weeks after the onset of pain in the chest which first came on after exertion but later occurred also at rest. On admission he had a blood pressure of 150/54. There was no evidence of cardiac failure. He had a normal erythrocyte sedimentation rate $(8 \mathrm{~mm}$./hour). He died unexpectedly six weeks after admission. During this time five electrocardiograms showed the pattern to change from that seen in $a$ to that in $b$. The terminal $\mathrm{T}$ wave inversion remained constant.

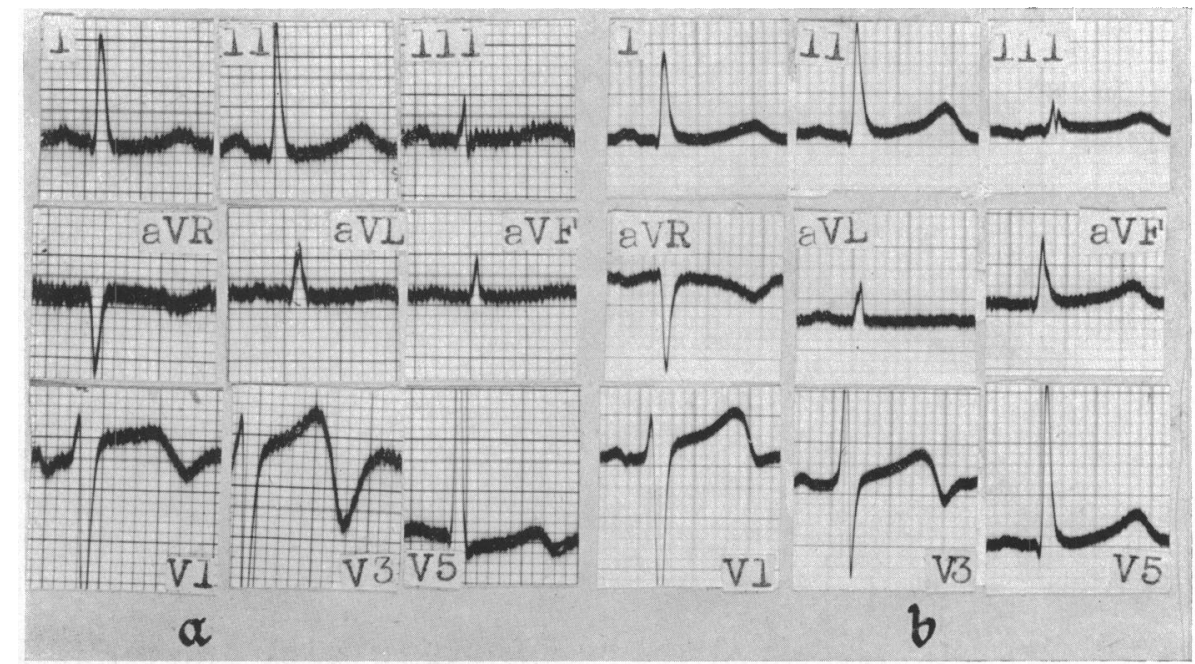

FIG. 3.-Case 1. History of myocardial infarction. (a) Earlier electrocardiographic changes. Deep T inversion V3. (b) Subsequent persistent change. Terminal depression TV3.

Post-mortem findings. No gross infarct was found macroscopically. A microscopic area of fibrosis well localized in the outer third of the anterior left ventricular wall (Fig. 4) was found to be present. In this area muscle fibres can be seen caught up in dense collagen tissue.

Comment. The pattern of terminal $\mathrm{T}$ depression in the præcordial lead V3 may therefore be taken to be the only indication of permanent muscle damage in the anterior wall of the heart. The situation of this damaged muscle supports the view that the terminal $\mathrm{T}$ arises from the more superficial heart muscle. Although this type of infarct is as liable to produce symptoms and signs, it is from its situation not as likely to cause severe complications such as perforation and endocardial thrombus formation with embolization. For this reason one would not be likely to meet this type of infarct frequently as a fresh one in the autopsy room. The cases that carry a good prognosis and do not require prolonged bed rest and continued anticoagulant therapy may have this type of infarct. Indeed, this type of graph can be seen to correspond very well with some of the published graphs of Papp and Smith (1951) in their discussions on cardiographic patterns in slight coronary attacks.

It would appear from the comparison of the effects of cooling the præcordium and the effects of muscle damage that very little interference may result in extensive $T$ wave changes, and that when $\mathrm{T}$ wave effects are the only cardiographic manifestation of muscle damage, the lesion is probably not large, and only superficial. This concept might permit less vigorous treatment.

Case 2. The electrocardiogram shown in Fig. 5a was taken while the patient, a man of 70, attended the out-patient department for angina of effort. This shows only the pattern of left ventricular hypertrophy. Graph (b) was taken two weeks after a severe nocturnal chest pain which had radiated to the throat and both arms. The duration of this pain had been 24 hours. 


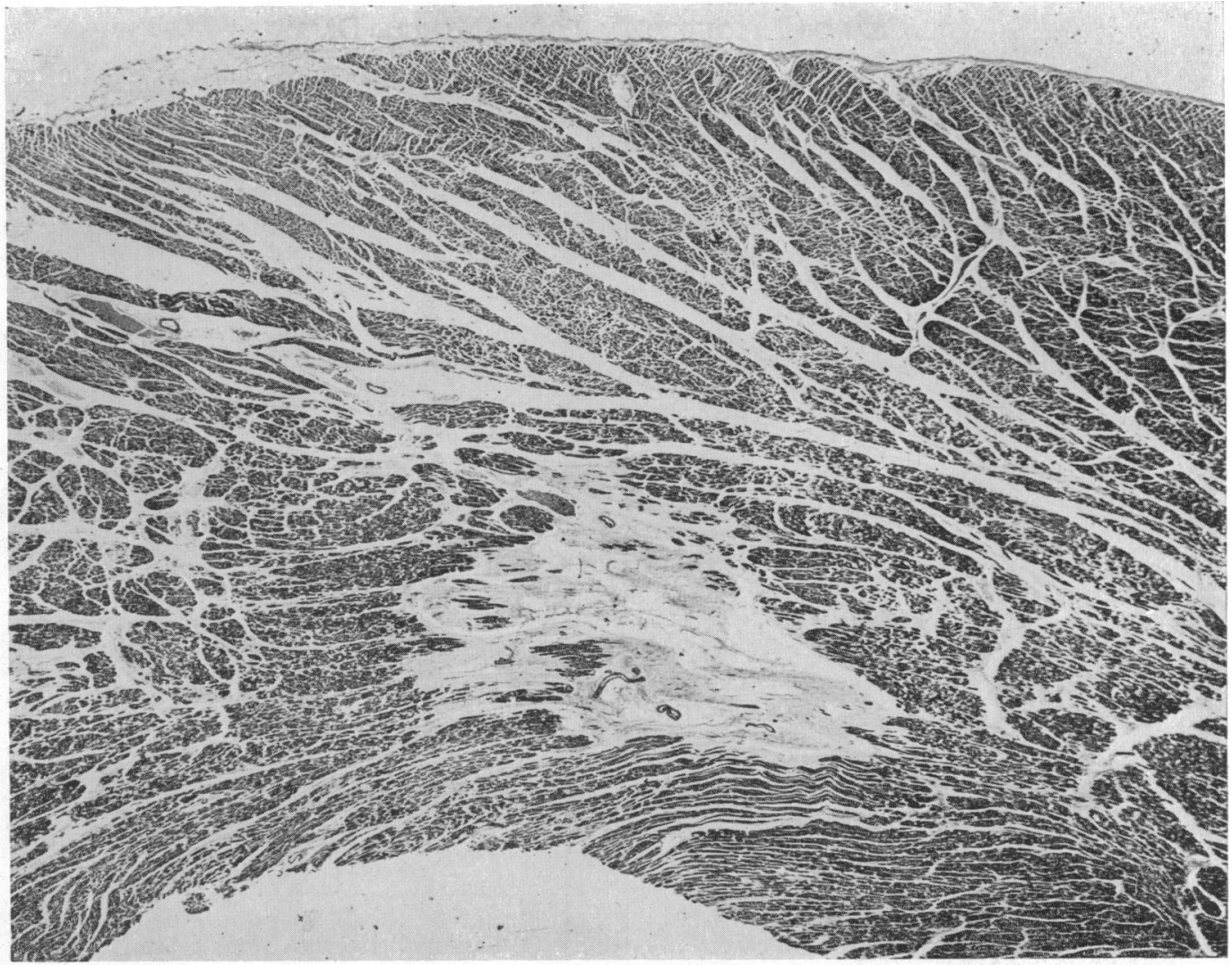

Fig. 4.-Microscopic section from anterior left ventricular wall of Case 1. Localized area of fibrosis. A few muscle fibres seem to be caught up in dense collagen tissue. Situation outer third of ventricular wall.

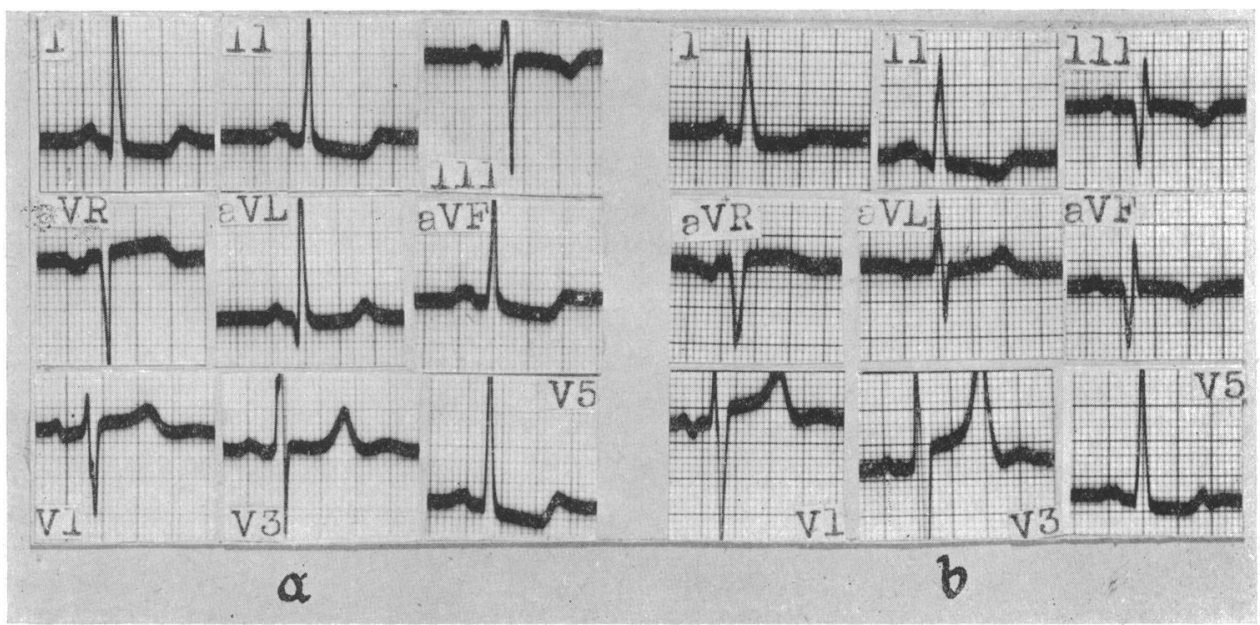

Fig. 5.-Case 2. (a) Pattern of left ventricular hypertrophy. (b) Two weeks after history of myocardial infarction shows a posterior infarction and tall TV3. 
The electrocardiogram has now changed remarkably, showing a QIII TIII and a QVF TVF pattern of a posterior myocardial infarct. The $\mathrm{T}$ wave in $\mathrm{V} 3 \mathrm{had}$ increased in amplitude from $5 \mathrm{~mm}$. to more than $15 \mathrm{~mm}$.

Comment. In this case the $\mathrm{T}$ in the præcordial lead is conspicuously augmented by a lesion in myocardial muscle situated in the heart wall opposite to that which is recorded electrocardiographically in V3.

Case 3. A man, aged 52 years, had episodes of severe substernal pain radiating down both arms into the wrists. They came on at rest and lasted 5 to 10 minutes. After several of these attacks over a period of twelve hours, he developed a more prolonged one which required morphia for relief, and he was then admitted to hospital. The first electrocardiogram taken (Fig. 6a) was

FIG. 6.-Case 3. History of myocardial infarction. (a) 24 hours after onset of symptoms. Tall TV3. (b) 18 days after (a). No further clinical incidents in the interim. Now shows anterior myocardial infarction.

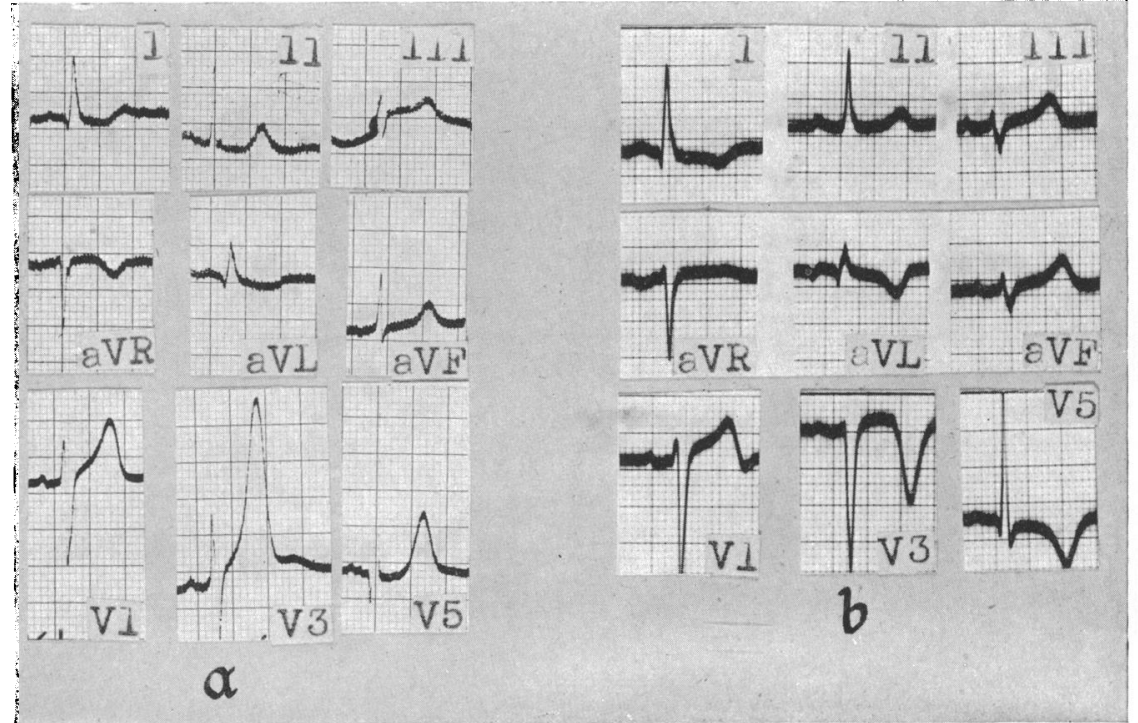

about 24 hours after the onset of these symptoms. The extraordinarily large amplitude of $\mathrm{T}$ in the præcordial leads, particularly V3 $(27 \mathrm{~mm}$.) was the only noteworthy feature at this stage. The leucocyte count rose to 23,000 per c.mm. The erythrocyte sedimentation rate, at first normal, went up to $52 \mathrm{~mm}$. in one hour after four days. The pain continued for three days, and thereafter there were no further recurrences. The next cardiogram (Fig. 6b) was taken 18 days after the first. The change in the præcordial $\mathrm{T}$ is quite obvious and the pattern now clearly resembles that of an extensive anterior infarct.

Comment. The first electrocardiographic effect of this anterior lesion had therefore been an augmentation of the $\mathrm{T}$ wave in the præcordial leads. This has previously been recorded (Wood and Wolferth, 1934) and could be interpreted as meaning an initial reactive hyperæmia in the damaged area.

\section{Discussion}

Three salient features emerge from the above descriptions of the effect of cooling and of local muscle damage. (1) The evidence produced suggests that the order of repolarization proceeds from the endocardial aspect to the pericardial aspect of the heart. (2) Effects in one region of muscle result in an alteration of the $T$ wave recorded from the opposing muscle mass. (3) When the muscle affected is superficial it is only the terminal $\mathrm{T}$ that shows any change.

Individual muscle bundles may therefore influence one another during the process of repolarization and in the formation of the $\mathrm{T}$ wave. They influence each other in such a way that opposing 
sides of the heart would appear to produce a balance between the forces that go to make the $T$ wave (Fig. 7). If this balance is upset the unaffected side escapes the normal damping effect of the opposite side, as is the case with the tall $\mathrm{T}$ in V3 in the posterior infarct (Fig. 5 and Fig. 7c). However, the reactive hyperæmia, which may appear early during a coronary thrombosis, may allow the repolarizing forces to predominate in the affected wall and result first in very tall $\mathrm{T}$ waves, as in Fig. 6. Later with ischæmia developing, the anterior wall has less influence than the posterior and the characteristic negative $T$ waves result (Fig. 6).

Since the more superficial myocardial muscle appears to be responsible for the end portion of the $T$ wave, a lesion affecting only these bundles may be expected to produce the terminal $T$ wave inversion as seen in Fig. $3 a$ and $b$. These patterns are seen to correspond accurately with the changes produced by the process of cooling (Fig. 2).

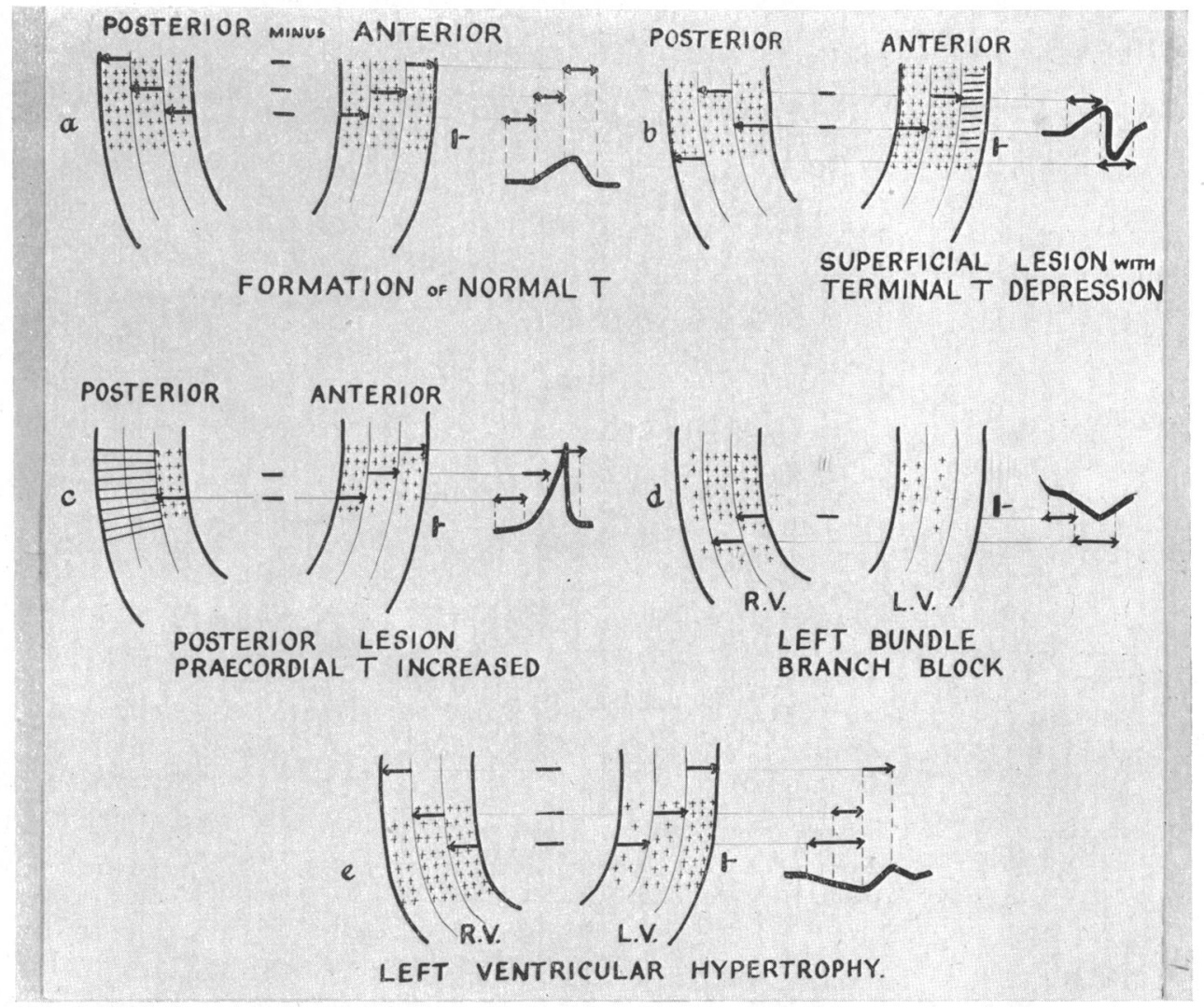

FIG. 7.-Diagrammatic representation of the spread of recovery process. (a) In the formation of normal $T$ wave. (b) In the production of the terminal $T$ depression by superficial lesion. (c) Augmentation of $\mathrm{T}$ in $\mathrm{V} 3$ by a posterior lesion. (d) Inversion of $\mathrm{T}$ in bundle branch block. (e) S-T depression and early T wave inversion in ventricular hypertrophy.

In the same way that activation spreads through the cardiac muscle from endocardial to pericardial aspect, so recovery proceeds in the same direction. Whereas the forces representing activation are rapid, the recovery process is about four times as slow (Craib, 1930). This means that the QRS complex represents the different phases of muscle bundle activation in successiona march of events - giving rise to the individual deflections and varying according to the site of the electrode. The $\mathrm{T}$ wave, however, is formed by the simultaneous contribution of muscle fibres undergoing recovery on all sides of the heart at the same time-a summation of events-and hence 
the contour of the $T$ is the same on all pericardial aspects of the heart. Where heart muscle is very close to the electrode, the forces arising here may predominate to such an extent that the $T$ is relatively tallest here and also leaves the base line earlier, resulting in a short S-T segment. This is frequently the case in positions $\mathrm{V} 2$ and $\mathrm{V} 3$.

The earliest recovery processes are to be expected in the subendocardial regions on all sides of the heart. Since they are spreading away from each other and are relatively far from the recording electrode, they would tend to cancel each other and be recorded as a straight line-the S-T segment (Fig. 7a). When the repolarization approaches more superficial areas it gradually has more and more influence on the recording electrode and the slowly rising limb of the $T$ wave takes place. The $\mathrm{T}$ deflection is therefore formed on all sides of the heart by the more peripheral muscle fibres only (Fig. 7a). For this reason probably, one can produce complete negativity of the $\mathrm{T}$ by merely cooling the superficial layers of heart muscle. Thus, also, relatively mild ischæmia of superficial areas may be the cause of extensive $T$ wave changes.

The S-T segment and early $\mathrm{T}$ deflection must therefore represent the forces of repolarization from subendocardial muscle fibres. When this portion of the electrocardiogram is primarily affected, we may therefore localize the site of the involved muscle in the deeper lying myocardium.

We may apply these principles in the interpretation of the $\mathrm{T}$ wave inversion in other conditions (Fig. 7 and 8).

1. Bundle branch block (Fig. 7). Here activation proceeds first to the normal side of the heart and hence these fibres will also be the first to start recovery. When the activating process reaches the blocked side and sets off recovery there, the normal ventricle has already a larger number of fibres undergoing repolarization, and will therefore predominate in influence on an electrode recording events from the blocked side with resulting negativity of the $T$ wave.

2. Ventricular hypertrophy (Fig. 7). Although the fibres become hypertrophied, their number remains the same. Many of them are relatively ischæmic because the capillary vessels do not multiply (Wearn, 1940). Repolarization forces from the hypertrophied side can therefore become only less in magnitude. This results in repolarizing forces from the normal ventricle, predominating in influence over those from the hypertrophied chamber, and therefore there is initial $\mathrm{T}$ wave negativity recorded over the hypertrophied ventricle. In the case of hypertrophy it can be observed that it is the early $\mathrm{T}$ which first becomes negative resulting in a biphasic down-up $\mathrm{T}$. This suggests that the deeper lying heart muscle becomes involved at an earlier date than the more superficial.

3. Digitalis effect. The changes here consist of a depression of the terminal S-T segment and early $T$ wave with a biphasic down-up deflection. When digitalis effect is seen in cases with left ventricular damage, the changes are almost invariably to be seen in the leads reflecting left ventricular potentials. Reciprocal changes are seen from the right ventricle. Judged electrocardiographically, digitalis seems to affect the more severely damaged fibres most, that is to say, those situated subendocardially and in the ventricle which is under stress. This is in accordance with the generally accepted view that digitalis has a greater effect on pathological material.

4. The inverted pracordial $T$ wave of normal children (Fig. $8 \mathrm{a}$ and b). In a series of 53 normal children between the ages of 16 months and 15 years, $T$ was inverted in præcordial leads as far as V4 in 5 cases. On inspecting the pattern of $T$ wave negativity in those cases where this deflection is not completely negative but biphasic it was found that the terminal $\mathrm{T}$ tended to be positive (Fig. 8b). This suggests that the last portion of heart muscle to recover and hence the last portion to become active, is the area underlying the electrode in positions V1 to V4. This is right ventricular muscle and it appears then that the $\mathrm{T}$ wave inversion may be explained by a degree of physiological right ventricular block.

5. The normally occurring inverted $T$ wave in adult Negro and South African Bantu. In a series of 100 normal adults from the Bantu races, 50 men and 50 women, ranging in age from 18 years to 50 years, the $\mathrm{T}$ deflection was found to be negative as far as V4 in 4 cases. Where these deflections are incompletely negative they show a biphasic pattern with depression of the terminal portion 


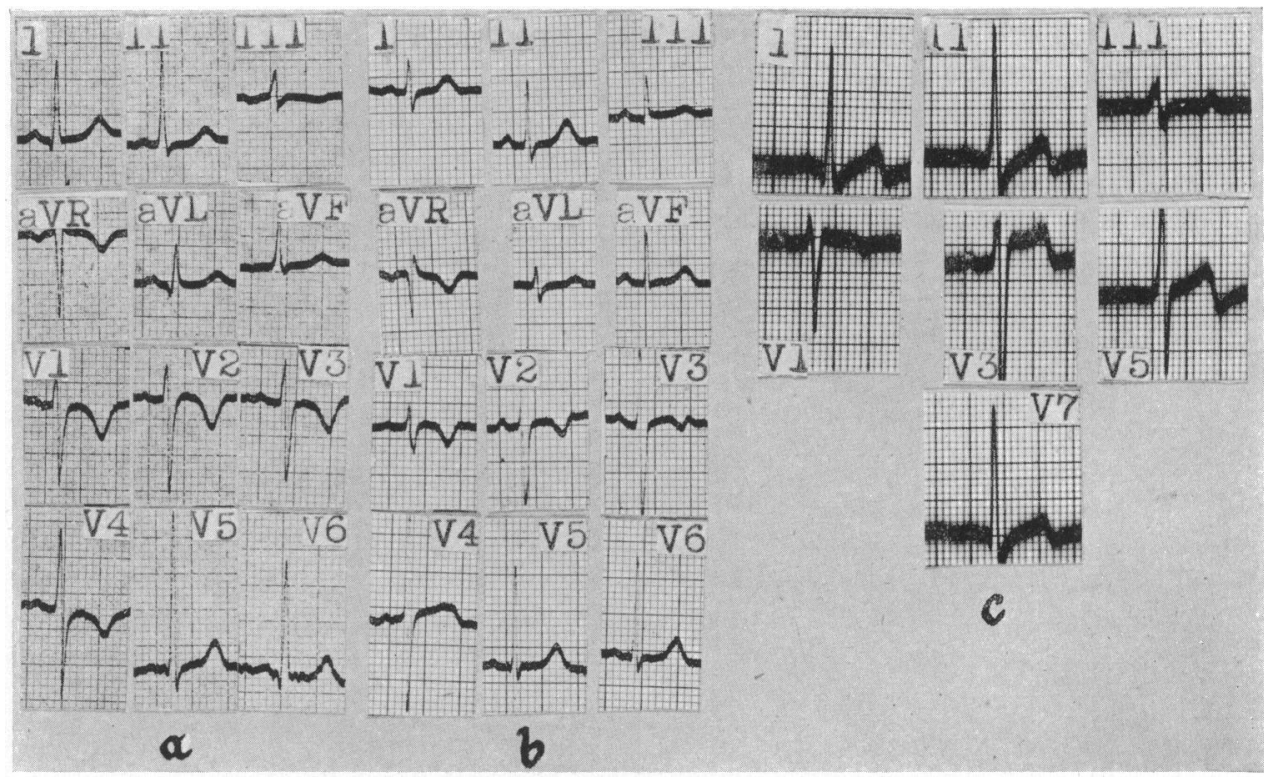

FIG. 8.-T wave inversion in the præcordial leads of normal children and adults of the Bantu race. (a) Child, aged 11 years. T negative V1 to V4. (b) Child, aged 7 years. Terminal portion of $\mathrm{T}$ position in V3. (c) Adult Bantu, aged 25 years. Terminal $\mathrm{T}$ negative in V3.

(Fig. 8c). This pattern contrasts with that found in normal children and it would appear that in the adult Bantu the negative præcordial $\mathrm{T}$ wave cannot be ascribed to a persistence of the juvenile pattern. Here the explanation may rest either with some mechanical influence of the anterior chest wall on the heart surface, or with greater repolarizing forces posteriorly. Increased blood supply may result in increase of the magnitude of the recovery forces as with the reactive hyperæmia (Fig. 6). The posterior wall of the Bantu heart is thought to be more richly endowed with blood vessels than in European races (Brink, 1949), and hence this may on accasion be sufficient reason for the negative præcordial $\mathrm{T}$ wave.

\section{SUMMARY}

The $\mathrm{T}$ wave in position V1 to V4 may be inverted by prolonged cooling of the anterior chest wall. The order in which this inversion takes place suggests that repolarization follows the same path as depolarization, namely, from within out. Small superficial areas of muscle damage in the anterior wall are shown to produce effects comparable to the cooling procedure.

$\mathrm{T}$ wave changes as the only indication of muscle damage are thought to represent only a superficial lesion. Such a lesion may not require a vigorous regime of treatment. Terminal T wave depression may be the only evidence of permanent muscle damage.

An analysis and interpretation is attempted of the formation of the normal $T$ wave and inversion occurring in such conditions as bundle branch block, ventricular hypertrophy, and digitalis effect, and in normal children and the adult Negro and Bantu.

\section{REFERENCES}

Ashman, R., and Hull, E. (1944), Essentials of Electrocardiography. 2nd. ed., New York : Macmillan Co. Brink, A. J. (1951). S. Afr. J. clin. Sci. (in press). (1949). Clin. Proc., 8, 137

Craib, W. H. (1930). M.R.C. Spec. Rep. Ser. No. 147. London : H.M.S.O.

Littmann, D. (1946). Amer. Heart J., 32, 370.

Papp, C., and Smith, K. Shirley (1951). Brit. Heart J., 13, 17.

Wearn, J. T. (1940). Harvey Lectures, 35, 242.

Wood, F. C., and Wolferth, C. C. (1934). Amer. Heart J., 9, 706. 